\title{
STEMI mimicker in a 26-year-old man
}

\author{
Hong Seok Lee, ${ }^{1,2}$ Ramdas Pai, ${ }^{2}$ Sami Nazzal, ${ }^{2}$ Ashis Mukherjee ${ }^{2}$
}

'Public Health, Johns Hopkins University Bloomberg School of Public Health, Baltimore, Maryland, USA

${ }^{2}$ Cardiology, University of California Riverside School of Medicine, Riverside, California, USA

\section{Correspondence to \\ Dr Hong Seok Lee, \\ Ihscd11@gmail.com}

Accepted 10 January 2019

\section{SUMMARY}

We herein describe a case of acute myocarditis which may mimic myocardial infarction, since affected patients experience 'typical' chest pain, the ECG changes are identical to those observed in acute coronary syndromes, and serum markers are increased. This case emphasises the importance of performing appropriate cardiac MRI to help in the differential and definitive diagnosis as well as the extent of myocardial involvement. ST elevation myocardial infarction is rare in young adults and when it is encountered, it should raise the differential diagnosis of its mimickers.

\section{BACKGROUND}

Cardiac MRI might have a greater evaluation value for diagnosis of acute myocarditis and and its extent. ${ }^{1}$ Cell-level change such as cell inflammation and tissue damage have all been involved in the setting of myocarditis. ${ }^{2}$ Distinction between acute myocardial infarction and myocarditis is based on the segment of wall-motion abnormalities. ${ }^{3}$ Prior clinical and pathological studies already have established the specificity of myocardial delayed enhancement on cardiac MRI in diagnosing acute myocarditis. ${ }^{4}$ Differential diagnosis of ST elevation myocardial infarction (STEMI) mimickers in our case should be entertained in a young patient presenting with STEMI. The MRI findings in our study were also inconsistent with myocardial infarction because the MRI did not demonstrate endomyocardial enhancement the pattern found in myocardial infarction. ${ }^{5}$ Myocarditis usually shows a characteristic pattern of contrast enhancement, which originates primarily from the epicardium, sparing the subendocardial layer. ${ }^{5}$ There was no significant relationship between the findings on transthoracic echocardiogram (TTE), cardiac MRI and the biochemical markers of myocardial damage. ${ }^{1}$ The meaningful relationship between ECG's ischaemic change and transmural myocardial oedema found in cardiac magnetic resonance in patients with clinically suspected acute

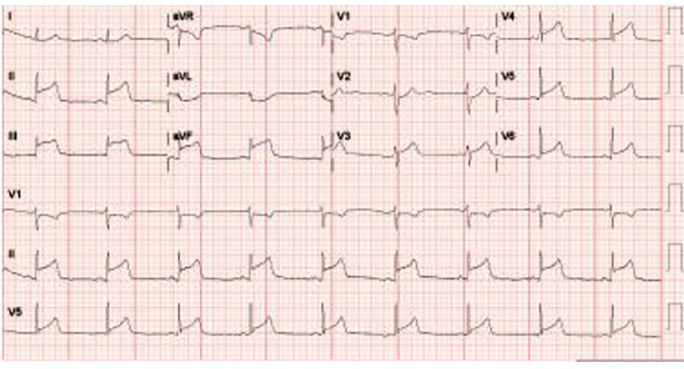

Figure 1 ST-segment elevation in leads II, III and aVF with V4-6 ST elevation and reciprocal change in V1, 2 suggests inferior myocardial infarction. myocarditis was reported, ${ }^{6}$ which could be applicable to our study (figures 1 and 2).

\section{CASE PRESENTATION}

A 26-year-old man with no medical history presented to the emergency room with acute central chest pain of 4 hours duration, waking him up from sleep. The ECG showed $3 \mathrm{~mm}$ ST elevation in the inferior leads. His physical examination was normal, and he was haemodynamically stable. The initial cardiac enzymes were elevated with troponin-I of $27.8 \mathrm{ug} / \mathrm{mL}$, Creatine Kinase (CK) 3265 units/L, and CK-MB (Creatine Kinase-muscle/brain) $67.1 \mathrm{ng} / \mathrm{dL}$. Though young, with no cardiac risk factors, he met the criteria for STEMI activation. He received aspirin, nitroglycerin, beta-blocker, high dose statin and intravenous heparin infusion in the emergency room and was taken to the cardiac catheterisation laboratory. Cardiac catheterisation showed normal coronary arteries with no obstruction or dissection. Transthoracic echocardiogram showed normal wall motion with left ejection fraction 60\%. Suspicion of myocarditis was entertained, and hence cardiac MRI was ordered. It showed left ventricle inferior base hypokinesis with transmural delayed enhancement, mild enhancement of distal lateral wall, proximal septum and anterior wall and pericardial enhancement in the inferior base and no pericardial effusion or thickening confirming a diagnosis of myopericarditis with transmural inflammation of the inferior base resulting in ST elevation and chest pain possibly because of intense regional pericarditis. Serological markers for coxsackievirus, adenoviruses, herpes virus, influenza virus, hepatitis C, parvovirus B 19, B. burgdorferi and antinuclear antibody came back negative subsequently. $\mathrm{He}$ responded rapidly to colchicine and high dose aspirin. Left ventricular inferior wall-motion abnormalities was moderately hypokinetic. Cardiac MRI is unique in that it provides non-invasive myocardial tissue characterisation based on the local chemical microenvironment. ${ }^{7}$ Delayed transmural enhancement was found predominantly in the inferior wall (figures 3 and 4). And it also showed in the mid-lateral wall and proximal septum and anterior wall. TTE findings was not correlated with cardiac MRI findings. The MRI in our patient was classic for myocarditis, with mid-myocardial enhancement of the septum, which spared the subendocardium and corresponded to the ECG changes, and wall-motion abnormality.

\section{INVESTIGATIONS}

Cardiac MRI is unique in that it provides non-invasive myocardial tissue characterisation based on the local chemical microenvironment. ${ }^{7}$ Delayed 




Figure 2 Normal sinus rhythm, 1 day after the first day of admission.

transmural enhancement was found predominantly in the inferior wall (figures 3 and 4). And it also showed in the mid-lateral wall and proximal septum and anterior wall. TTE findings was not correlated with cardiac MRI findings. The MRI in our patient was classic for myocarditis, with mid-myocardial enhancement of the septum, which spared the subendocardium and corresponded to the ECG changes, and wall-motion abnormality.

\section{DIFFERENTIAL DIAGNOSIS}

Serological markers for coxsackievirus, adenoviruses, herpes virus, influenza virus, hepatitis C, Parvovirus B 19, B. burgdorferi and antinuclear antibody came back negative subsequently.

\section{TREATMENT}

He responded rapidly to colchicine and high dose aspirin for treatment of myocarditis.

\section{OUTCOME AND FOLLOW-UP}

No follow-up so far. But No more emergency department visit so far.

\section{DISCUSSION}

Focal myocarditis, cardiac sarcoid, coronary or aortic dissection, coronary arteritis and coronary embolism can produce

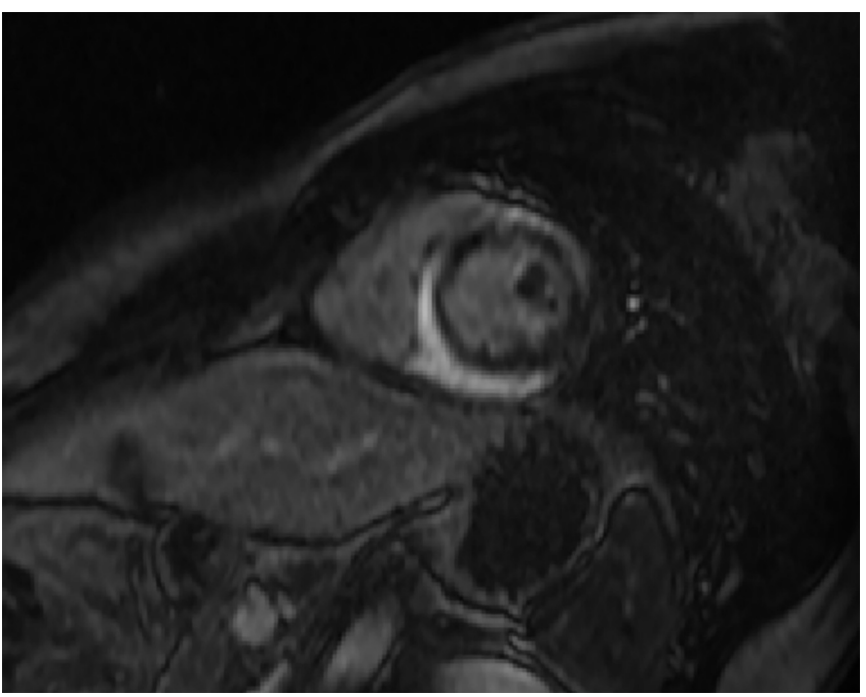

Figure 3 Late gadolinium cardiac MRIs in two-chamber and long axis planes demonstrating transmural myocardial gadolinium enhancement in the inferior wall; classic MRI features of myocarditis.

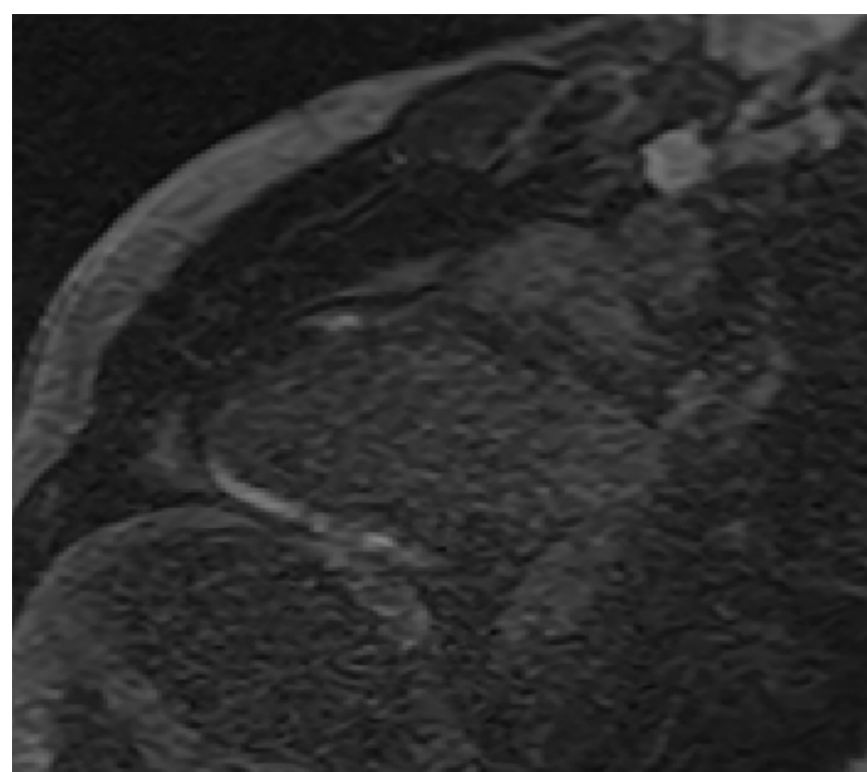

Figure 4 Late gadolinium cardiac MRIs in short axis planes demonstrating transmural myocardial gadolinium enhancement in the inferior wall; classic MRI features of myocarditis.

STEMI or STEMI-like syndrome, and appropriate multimodality imaging may help in the differential and definitive diagnosis. We conclude that cardiac MRI provides non-invasive imaging that may obviate invasive procedures such as coronary catheter angiography or endomyocardial biopsy.

\section{Learning points}

ST elevation myocardial infarction is rare in young adults and when it is encountered, it should raise the differential diagnosis of its mimickers.

- No correlation was found between the degree or extent of imaging findings on transthoracic echocardiogram, cardiac MRI.

- The meaningful relationship between ECG's ischaemic change and transmural myocardial oedema as evidenced by cardiac magnetic resonance in patients with clinically suspected acute myocarditis should be considered.

- MRI could be one of the modalities to make diagnosis and lead to better management.

Contributors HSL mainly wrote this manuscript and, SN, AM and RP contributed to writing this article and finding references equally.

Funding The authors have not declared a specific grant for this research from any funding agency in the public, commercial or not-for-profit sectors.

Competing interests None declared.

Patient consent for publication Not required.

Provenance and peer review Not commissioned; externally peer reviewed.

\section{REFERENCES}

1 De Lazzari M, Zorzi A, Baritussio A, et al. Relationship between T-wave inversion and transmural myocardial edema as evidenced by cardiac magnetic resonance in patients with clinically suspected acute myocarditis: clinical and prognostic implications. J Electrocardiol 2016:49:587-95.

2 Franco A, Javidi S, Ruehm SG, et al. Delayed Myocardial Enhancement in Cardiac Magnetic Resonance Imaging. J Radio/ Case Rep 2015;9:6-18.

3 Goitein 0, Matetzky S, Beinart R, et al. Acute myocarditis: noninvasive evaluation with cardiac MRI and transthoracic echocardiography. AJR Am J Roentgenol 2009;192:254-8. 
4 Hiramitsu S, Morimoto S, Kato S, et al. Significance of transient left ventricular wall thickening in acute lymphocytic myocarditis. Heart Vessels 2007;

22:25-9.

5 Hoey ET, Shahid M, Ganeshan A, et al. MRI assessment of cardiac tumours: part 1, multiparametric imaging protocols and spectrum of appearances of histologically benign lesions. Quant Imaging Med Surg 2014;4:478-88.
6 Khan TA, Chowdhury AW, Khan HILR, et al. Echocardiographic comparison of regional wall motion abnormality between patients with acute anteroseptal and acute extensive anteior ST segment elevation myocardial infarction. Bangladesh Med Res Counc Bull 2015;41:35-40

7 Laissy JP, Messin B, Varenne 0 , et al. MRI of acute myocarditis: a comprehensive approach based on various imaging sequences. Chest 2002;122:1638-48.

Copyright 2019 BMJ Publishing Group. All rights reserved. For permission to reuse any of this content visit https://www.bmj.com/company/products-services/rights-and-licensing/permissions/

BMJ Case Report Fellows may re-use this article for personal use and teaching without any further permission.

Become a Fellow of BMJ Case Reports today and you can:

- Submit as many cases as you like

- Enjoy fast sympathetic peer review and rapid publication of accepted articles

- Access all the published articles

Re-use any of the published material for personal use and teaching without further permission

For information on Institutional Fellowships contact consortiasales@bmjgroup.com

Visit casereports.bmj.com for more articles like this and to become a Fellow 